\title{
A Role for Histone Chaperones in Regulating RNA Polymerase II
}

\author{
JoDi Lynn Osborn, Susanna F. Greer \\ Department of Biology, Georgia State University, Atlanta, USA \\ Email: sgreer@gsu.edu
}

Received 31 December 2014; accepted 23 February 2015; published 2 March 2015

Copyright (C) 2015 by authors and Scientific Research Publishing Inc.

This work is licensed under the Creative Commons Attribution International License (CC BY). http://creativecommons.org/licenses/by/4.0/

(c) (i) Open Access

\begin{abstract}
Transcription is a highly regulated cellular process in which dysfunction leads to disease. One level of regulation is chromatin structure which protects promoters from transcription factor binding. To circumvent this blockade, histone chaperones aid in displacement of nucleosomes. In particular, the histone chaperone complex HUCA, consisting of Hira, Ubn1, Cabin1, and ASF1a, replaces histone variant H3.1 with H3.3 in front of actively transcribing RNA Polymerase II (RNAPII). The $26 \mathrm{~S}$ proteasome is a major degrader of proteins within the cell and plays both proteolytic and nonproteolytic roles in transcriptional regulation. One major role is the degradation of irreversibly arrested RNAPII. Several interactions between HUCA, the 26 S proteasome, and RNAPII have been characterized individually; we now present observations from our lab and others which directly associate elongating RNAPII with the degradation machinery through observations of involvement with the HUCA complex. Our short report presents these ideas and discusses their importance in transcriptional regulation as well as implications in disease manifestation.
\end{abstract}

\section{Keywords}

Histone Chaperones, RNA Polymerase II, 26S Proteasome, Transcriptional Regulation

\section{Introduction}

Cellular function is highly dependent on regulated gene expression which is controlled by the coordinated efforts of thousands of proteins including transcription factors, cofactors, and chromatin regulators. The coordinated efforts and interactions of these proteins control cell fate and cellular responses to physiological or environmental changes. One level at which protein interaction, and thus gene expression, is ordered is control of transcription factor accessibility to DNA by chromatin (Reviewed in [1]).

Despite over half a century of research in transcriptional regulation, the intricate details of the system have 
not been fully elucidated. Our proposed model addresses the regulatory interactions between RNA Polymerase II, the histone chaperone complex HUCA, and the 26S Proteasome. We hypothesize that the histone chaperone HUCA tethers the 26S proteasome to elongating RNAPII to facilitate rapid degradation in the case of irreversibly arrested RNAPII. A schematic of the proposed mechanism is provided in Figure 1. Disassembly of RNAPII elongation complexes has previously been linked to the ATPase Cdc48 with proposed roles for ubiquitination in dissociating Rpb1 from the complex [2]. The 26S proteasome binds transcribing genes at locations enriched with RNAPII [3], 19S and 20S subunits of the proteasome bind promoters, ORFs, and termination regions [3]-[6]. In C. elegans, RNAPII is found localized in "degradation centers" where blocked transcription initiates proteasome mediated degradation [7]. Thus, components of the proteasome are linked with chromatin in multiple and overlapping contexts. Each of these observations suggests that removal of proteins from chromatin and degradation of at least some of these proteins, is likely to be a common theme in the regulation of gene expression.

\section{Chromatin Organization and Histone Modifications}

The basic unit of chromatin is the nucleosome which consists of 147 base pairs of DNA wrapped around a histone octamer of two dimers each of canonical histones H2A, H2B, H3, and $\mathrm{H} 4$ as well as the linker histone $\mathrm{H} 1$ [8]. Nucleosomes are packaged into higher order chromatin structures; modulation of which influences transcriptional outcomes. The N-terminal tails of histones undergo multiple covalent modifications including acetylation, methylation, sumoylation, ADP-ribosylation, and ubiquitination which can positively or negatively affect protein binding to DNA [9]. Different combinations of these histone marks dictate whether the chromatin is relaxed, allowing access by transcription factors, or closed, preventing transcription (Reviewed in [10]).

In addition to the impact of histone modifications on chromatin structure, nucleosome positioning poses an inherent block to elongating RNA Polymerase II (RNAPII) [11]. Nucleosomes are arranged in regularly spaced intervals, with the length of intervening linker regions between nucleosomes varying between species and cell types [12]. In general, nucleosomes are depleted at many enhancers and promoters and occupy preferred positions within genes [13]. Nucleosome occupancy differs in that it is a reflection of the depletion of nucleosomes from functional regions of genes and is critical to transcriptional outcomes. Access of RNAPII and other

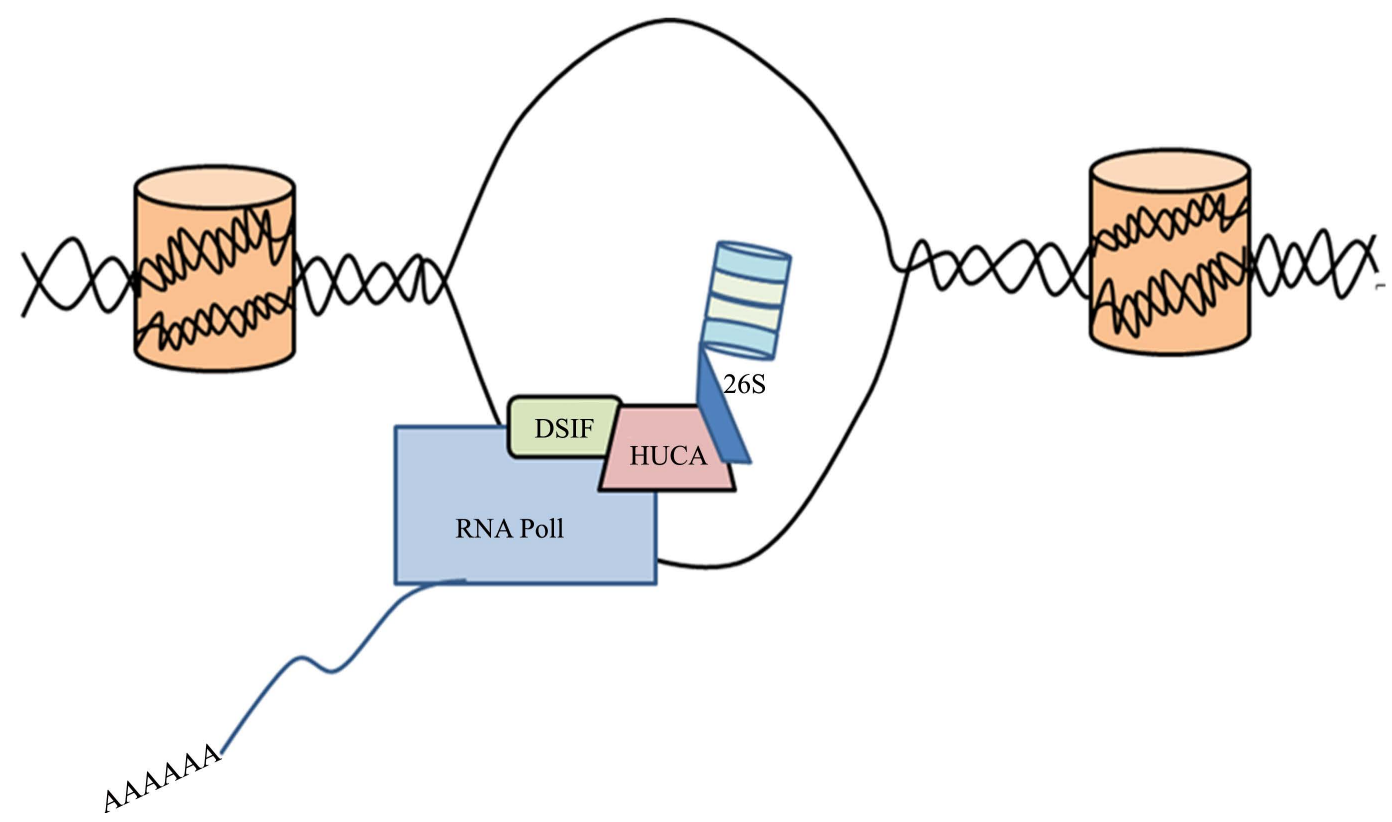

Figure 1. Proposed Mechanism. The histone chaperone HUCA tethers the 26S proteasome to elongating RNA Polymerase II to facilitate rapid degradation in the case of irreversible stalling of the RNA Pol II elongation complex. By keeping the cellular degradation machinery in close proximity, stalled RNA Pol II can be quickly degraded, thus avoiding continual repeat transcription and the accumulation of abnormal proteins within the cell. 
DNA-binding proteins to DNA is inhibited by nucleosomes and RNAPII is unable to mediate nucleosome eviction on its own [14] [15]. To assist RNAPII passage, chromatin remodelers and histone chaperones aid in removal of the nucleosome blockade. Chromatin remodelers unwind DNA from nucleosomes in an ATP-dependent manner [16] whereas histone chaperones are enzymes that facilitate exchange of histone variants during transcription in a histone-dependent, ATP-independent manner [17]. In addition to histone modifications and chromatin remodeling, replacement of canonical core histones with specialized variants assists in regulation of the open or closed states of chromatin [18] [19].

\section{Histone Chaperones: Multi-Faceted Roles}

Because nucleosome assembly and disassembly regulate chromatin dynamics, histone exchange is coordinated by multiple histone chaperones and their many functional partners. Histone chaperones form multi-subunit complexes and perform a multitude of functions depending on binding partners [20]. While their main role is to facilitate nucleosome disassembly and reassembly, their secondary roles lie in a variety of processes such as transcriptional regulation, cellular senescence, histone variant deposition, cell cycle regulation, DNA replication and repair, mRNA processing, and gene silencing [17] [21]. The dynamic role of chromatin itself highlights the need for histone chaperones to serve versatile roles in modulating the many complexes that regulate chromatin dynamics and subsequent pathways. One such example of a multi-faceted histone chaperone is the HUCA complex. HUCA is known to be critical in chromatin reorganization; we now further postulate HUCA to be of equal importance in regulating RNAPII processivity and arrest.

\section{HUCA Complex: An Important but Not Fully Understood Histone Chaperone Complex}

Histone chaperones work in concert with one another and other proteins to perform a multitude of cellular functions [20]. One such histone chaperone complex is HUCA, which consists of the histone chaperone Histone Regulatory A (HIRA), $\underline{\text { Ubinuclein }} 1$ (UBN1), $\underline{\text { Calcineurin binding }} 1$ (CABIN1), and the histone chaperone $\underline{A}-$ ti-silencing factor 1a (ASF1a) [22]-[24]. Human HIRA is an evolutionarily conserved fusion of Hir1 and Hir2 which form a nucleosome remodeling complex in lower eukaryotes [25]. The N-terminal Hir1-like domain consists of seven WD40 repeats [26]. Immediately following the di-peptide WD repeats is a 37 amino acid domain known as the B-domain [22]. The C-terminal Hir2-like domain consists of a leucine zipper (LXXLL motif) [27]. It is via these functional domains that HIRA acts as a scaffold around which other complex subunits form [22] [28]. UBN1 is an ortholog of the yeast protein Histone promoter control 2 (Hpc2) and contains an evolutionarily conserved Hpc2-related domain (HRD) [28]. The N-terminal region of UBN1 binds the WD40 repeats of HIRA as well as histone tails [23]. CABIN1 is a functional ortholog of Hir3p but the only structural similarity is 30 tetratricopeptide repeats (TPR) at the N-terminus [18]. The TPR domain of CABIN1 interacts with the C-terminus of HIRA [24]. ASF1a has an evolutionarily conserved immunoglobulin fold at its N-terminus and a divergent, species specific, C-terminus [29]. ASF1a binds HIRA via interaction of its N-terminal sequence with the B domain of HIRA [22]. For a schematic of the HUCA complex and its components, see Figure 2. HIRA binds the promoters of histone genes and prevents their transcription outside of S-phase [30] [31]. The mechanism of histone promoter silencing is through blockade of the SWI/SNF complex which is required for transcription of histone genes during S-phase [32]. This was initially shown for histones H2A and H2B but is not the case for histone H3.3 which is transcribed throughout the entire cell cycle [33]. HIRA simultaneously binds DNA and RNAPII while depositing histone H3.3 during transcription [34]. The ability of HIRA to bind DNA non-specifically has been implicated in prevention of cryptic transcription in Schizosaccharomyces pombe [35]. Heterogenous HIRA expression leads to DiGeorge Syndrome in humans and has been implicated in developmental impediments in Drosophila melanogaster, Gallus gallusdomesticus, and Mus musculus [36]-[38]. Complete knockout of HIRA is lethal as early as embryonic development day 10 [38].

In addition to its role in the histone chaperone HUCA complex, ubinuclein 1 has been posited to be a histone chaperone in its own right [39]. UBN1 has also been shown to act as a scaffold protein and to play a role in cellcell adhesion in canine kidney cells [40] [41]. CABIN1 has recently been classified as a member of the HUCA complex and implicates regulation of this histone chaperone complex by intracellular calcium [24] [42]. ASF1a, which is also a histone chaperone, binds H3.1, H3.2, and H3.3 and plays roles in nucleosome eviction in both DNA-replication and transcription [22] [43]. In addition to its role in nucleosome eviction, ASF1 has been 
HIRA

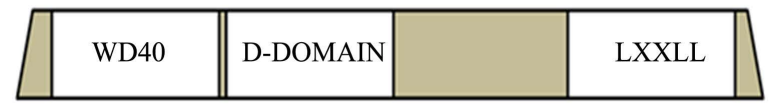

UBN1

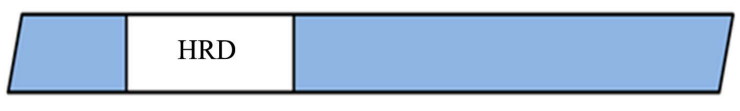

CABIN1

TPR

ASF1
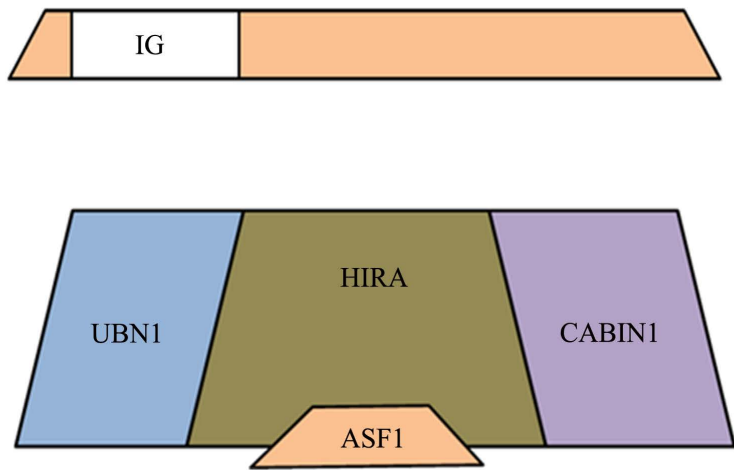

Figure 2. Schematic of the HUCA Complex. HUCA is composed of the histone chaperone Histone Regulatory A (HIRA), Ubinuclein 1 (UBN1), calcineurin binding 1 (CABIN1), and the histone chaperone Anti-silencing Factor 1 (ASF1). HIRA acts as a scaffold around which the other complex subunits form. The N-terminal domain of UBN1 binds the N-terminal WD repeats of HIRA. The TPR domain of CABIN1 interacts with the C-terminus of HIRA and ASF1 binds the B-domain of HIRA.

shown to play roles in regulating acetylation in both histones H3 and H4 in Saccharomyces cerivisiae [20]. Despite the elucidation of various roles of HUCA components, specific regulatory roles of the complex as a whole are not understood.

\section{Transcriptional Elongation by RNA Polymerase II (RNAPII)}

RNAPII transcribes mRNA from a DNA template in all protein-encoding genes. Transcription relies on a coordinated network of histone modifying enzymes and histone chaperones to allow elongating RNAPII to traverse the chromatin landscape. In particular, HUCA deposits the histone variant H3.3 in front of elongating RNPII to facilitate transcription through nucleosome complexes [34]. Transcription proceeds in three distinct stages: initiation, elongation, and termination [44]. The pre-initiation complex (PIC) which forms at the gene promoter, contains RBP1 and the general transcription factors (GTFs) TFIIB, TFIID, TFIIE, and TFIIH [45]. Other factors are also present including DRB Sensitivity Inducing Factor (DSIF) and Negative Elongation Factor (NELF) which positively [46] and negatively [47] regulate RNAPII, respectively. The C-terminal domain (CTD) of RBP1 consists of 52 repeats of the heptapeptide $\mathrm{Y}_{-} \mathrm{S}_{2}-\mathrm{P}-\mathrm{S}_{5}-\mathrm{T}-\mathrm{P}-\mathrm{S}$ [48]. Phosphorylation status of the serine residues within the CTD correlates with transcriptional activity. Serine 5 phosphorylation (Ser5ph) by the cyclin dependent kinase 7 (cdk7) subunit of TFIIH leads to transcriptional initiation by recruitment of factors that faci- 
litate escape from the promoter [49]. Initial transcription can be non-productive until the formation of an 8 to 9 bp hybrid of the DNA template and the nascent mRNA [50]. Serine 2 is phosphorylated (ser2ph) by the cdk9 subunit of Positive Transcription Elongation Factor b (P-TEFb) which stimulates productive elongation [51], in part by triggering the release of NELF [52].

\section{The Three States of RNAPII: Paused, Stalled, and Arrested}

Regulation of chromatin states by histone remodelers and histone chaperones is only one level at which transcription elongation can be controlled. In addition to blocking RNAPII access to DNA, RNAPII processivity regulates transcription. Early studies of heat shock proteins showed that RNAPII is present at the promoter prior to induction [53]. Subsequent studies have shown that RNAPII is paused at the promoters of other stimulus-responsive genes [54]. Pausing is mediated by DRB-Sensitivity Inducing Factor (DSIF) and Negative Elongation Factor (NELF). NELF preferentially binds hypophosphorylated RNAPII and is required for promoter-proximal pausing [55]. The two major causes of RNAPII stalling are lesions in the DNA template and nucleotide misincorporation. Lesions in the template cause RNAPII to stall until transcription-coupled DNA repair can occur [56]. The stalled RNAPII remains bound to the DNA template and once the lesion has been excised and repaired, elongation can resume [57] [58]. Nucleotide misincorporation stalls RNAPII by causing it to backtrack one base pair [59] [60]. TFIIS stimulates RNAPII to hydrolytically cleave the misincorporated nucleotide [61]. After cleavage, the newly formed 3' end is prepared for the addition of the appropriate nucleotide, a process which occurs rapidly and has been termed "kinetic proofreading" [62]. Pausing and stalling of RNAPII are mediated by both histone chaperones and the $26 \mathrm{~S}$ proteasome. In the event that stalled RNAPII cannot resume elongation, RNAPII becomes irreversibly arrested and is poly-ubiquitinated and tagged for degradation by the $26 \mathrm{~S}$ proteasome [63] [64].

\section{Ubiquitination of RNAPII and Degradation by the 26S Proteasome}

Arrested RNAPII is tagged for degradation by the addition of four ubiquitin moieties linked by lysine 48 (K48linkage) [65]. Poly-ubiquitination is the concerted effort of three types of enzymes: ubiquitin-activating (E1), ubiquitin-conjugating (E2), and ubiquitin-ligase (E3) [65]. RNAPII poly-ubiquitination is unique in that it occurs in a sequential manner involving two different E3 ligases. Neural precursor cell Expressed Developmentally Downregulated 4 (NEDD4) mono-ubiquitinates RNAPII [66] and then Elongin/Cullin converts this monoubiquitination to poly-ubquitination [67] [68]. Ubiquitination of RNAPII occurs on its largest subunit Rpb1 and only occurs when the polymerase is irreversibly arrested (reviewed in [69]).

\section{The 26S Proteasome: Degrader of Proteins}

The 26S proteasome is the major non-lysosomal player in degradation of damaged or unnecessary proteins within the cell including RNAPII [65]. The 26S proteasome also plays roles in transcription initiation by controlling the location and quantity of available transcription factors [70]. The 26S proteasome is composed of three distinct sub-complexes: the 19S regulatory particle (RP) lid, the 19S RP base, and the 20S catalytic particle (CP) [71]. The 19S RP lid is composed of 9 unique subunits: Regulatory Particle Non-ATPase 3 (Rpn3), Rpn5-9, Rpn11-12 and Rpn15 [71]. The 19S base consists of a hexameric ring of AAA ATPases (RPT1-6) and three non-ATPase subunits and is connected to the 19S RP lid by the linker protein Rpn10 [71] [72]. The 20S catalytic particle (CP) is a barrel-shaped complex composed of four heptameric rings composed of either $\alpha$ or $\beta$ subunits stacked in an $\alpha \beta \beta \alpha$ conformation [71].

\section{Interactions between HUCA, the 26S Proteasome, and RNAPII}

Several interactions between HUCA, the 26S proteasome, and RNAPII have been characterized. Liquid chromatography tandem mass spectrometry revealed that all six ATPase subunits of the 19S RP base co-purify with HIRA in S. pombe [73]. The interaction between the 19S ATPases and HIRA is thought to counteract the repressive functions of HIRA on histone genes, but this role has yet to be further studied [73]. We have further verified interactions between the 19S ATPases and HIRA in co-immunoprecipitation assays in mammalian cells (Osborn and Greer, unplublished). ChIP-seq density profiles followed by co-immunoprecipitation show that multiple subunits of the HUCA complex bind to both the initiating and elongating forms of RNAPII [74]. The 
importance of the interaction between HUCA and RNAPII is underscored by the fact that in yeast cells depleted of HIRA, RNAPII recruitment is impaired [75]. HIRA binds to both subunits of DSIF [76] which travels throughout the coding region along with RNAPII [77]. Additionally, HIRA interacts directly with the elongation factors SPT6 and SPT16 [76] [78]. Finally, the ASF1a subunit of HUCA interacts directly with the bromodomain of CCG1, the largest subunit of TFIID [79].

Recent studies from our lab and others are the first to directly associate elongating RNAPII with the degradation machinery through observations of the involvement of the HUCA chaperone complex. We propose that the HUCA complex tethers the 26S Proteasome to elongating RNAPII to enable rapid recognition and degradation of RNAPII by the proteasome. In addition to non-proteolytic roles in transcription (reviewed in [80]), tethering of the 26S proteasome to elongating RNAPII would facilitate its rapid degradation upon arrest. Recent observations of a novel Ubiquitin-independent proteasome pathway suggest that elongating RNAPII stalls at Topoisomerase II $\beta$-DNA cleavage complexes where blocked RNAPII serves as a damage signal and associated 19S ATPases are activated as an early event during the encounter for detecting the Topoisomerase II $\beta$ roadblocks [81] [82]. The 19S ATPases have also been proposed to unfold non-covalent protein-DNA nucleosome complexes during elongation; we suggest the ATPases and HUCA serve these and much earlier roles in allowing consistent tethering of RNAPII to the degradation machinery.

\section{Concluding Remarks}

While the molecular basis for interactions among stalled elongation, proteasomal degradation, and HUCA remains to be elucidated, understanding roles for 19S ATPases in mediating degradation of RNAPII will contribute therapeutically to multiple disease scenarios. In Cockayne syndrome, irreversibly arrested RNAPII leads to transcription anomalies resulting in phenotypes ranging from subtle to severe [83]. Additionally CAG repeat diseases such as Huntington disease and Spinocerebellar Ataxias are caused, in part, by repeated transcription by arrested RNAPII [84]. While diseases such as Cockayne Syndrome and CAG repeat disorders have transcriptional arrest as an underlying cause, the molecular mechanisms of decreased transcript fidelity leading to disease manifestation have not been further investigated. In addition, several cancer therapeutics including etoposide/ VP-16 and doxorubicin stabilize topoisomerase II $\beta$-DNA cleavage complexes and trigger degradation of topoisomerase II $\beta$, the large subunit of RNAPII, and exposure of DNA damage [85] [86]. These drugs and the DNA damage they cause are associated with severe side effects; better understanding of the mechanisms by which these drugs initiate degradation will contribute to their enhanced clinical application.

\section{Acknowledgements}

J.L.O. was supported by a Graduate Fellowship from the Molecular Basis of Disease Area of Focus at Georgia State University. Grant support provided by a Research Scholar Grant from the American Cancer Society to S.F.G.

\section{References}

[1] Petesch, S.J. and Lis, J.T. (2012) Overcoming the Nucleosome Barrier during Transcript Elongation. Trends in Genetics, 28, 285-294. http://dx.doi.org/10.1016/j.tig.2012.02.005

[2] Verma, R., Oania, R., Fang, R., Smith, G.T. and Deshaies, R.J. (2011) Cdc48/p97 Mediates UV-Dependent Turnover of RNA Pol II. Molecular Cell, 41, 82-92. http://dx.doi.org/10.1016/j.molcel.2010.12.017

[3] Auld, K.L., Brown, C.R., Casolari, J.M., Komili, S. and Silver, P.A. (2006) Genomic Association of the Proteasome Demonstrates Overlapping Gene Regulatory Activity with Transcription Factor Substrates. Molecular Cell, 21, 861871. http://dx.doi.org/10.1016/j.molcel.2006.02.020

[4] Collins, G.A. and Tansey, W.P. (2006) The Proteasome: A Utility Tool for Transcription? Current Opinion in Genetics \& Development, 16, 197-202. http://dx.doi.org/10.1016/j.gde.2006.02.009

[5] Gillette, T.G., Gonzalez, F., Delahodde, A., Johnston, S.A. and Kodadek, T. (2004) Physical and Functional Association of RNA Polymerase II and the Proteasome. Proceedings of the National Academy of Sciences of the United States of America, 101, 5904-5909. http://dx.doi.org/10.1073/pnas.0305411101

[6] Krogan, N.J., Lam, M.H., Fillingham, J., Keogh, M.C., Gebbia, M., Li, J., et al. (2004) Proteasome Involvement in the Repair of DNA Double-Strand Breaks. Molecular Cell, 16, 1027-1034. http://dx.doi.org/10.1016/j.molcel.2004.11.033

[7] Scharf, A., Grozdanov, P.N., Veith, R., Kubitscheck, U., Meier, U.T. and von Mikecz, A. (2011) Distant Positioning of 
Proteasomal Proteolysis Relative to Actively Transcribed Genes. Nucleic Acids Research, 39, 4612-4627. http://dx.doi.org/10.1093/nar/gkr069

[8] Luger, K., Mader, A.W., Richmond, R.K., Sargent, D.F. and Richmond, T.J. (1997) Crystal Structure of the Nucleosome Core Particle at 2.8 A Resolution. Nature, 389, 251-260. http://dx.doi.org/10.1038/38444

[9] Bannister, A.J. and Kouzarides, T. (2011) Regulation of Chromatin by Histone Modifications. Cell Research, 21, 381395. http://dx.doi.org/10.1038/cr.2011.22

[10] Zentner, G.E. and Henikoff, S. (2013) Regulation of Nucleosome Dynamics by Histone Modifications. Nature Structural \& Molecular Biology, 20, 259-266. http://dx.doi.org/10.1038/nsmb.2470

[11] Kireeva, M.L., Walter, W., Tchernajenko, V., Bondarenko, V., Kashlev, M. and Studitsky, V.M. (2002) Nucleosome Remodeling Induced by RNA Polymerase II: Loss of the H2A/H2B Dimer during Transcription. Molecular Cell, 9, 541-552. http://dx.doi.org/10.1016/S1097-2765(02)00472-0

[12] Kelly, T.K., Liu, Y., Lay, F.D., Liang, G., Berman, B.P. and Jones, P.A. (2012) Genome-Wide Mapping of Nucleosome Positioning and DNA Methylation within Individual DNA Molecules. Genome Research, 22, 2497-506. http://dx.doi.org/10.1101/gr.143008.112

[13] Fenouil, R., Cauchy, P., Koch, F., Descostes, N., Cabeza, J.Z., Innocenti, C., et al. (2012) CpG Islands and GC Content Dictate Nucleosome Depletion in a Transcription-Independent Manner at Mammalian Promoters. Genome Research, 22, 2399-2408. http://dx.doi.org/10.1101/gr.138776.112

[14] Chang, C.H. and Luse, D.S. (1997) The $\mathrm{H}_{3} / \mathrm{H}_{4}$ Tetramer Blocks Transcript Elongation by RNA Polymerase II in Vitro. The Journal of Biological Chemistry, 272, 23427-23434. http://dx.doi.org/10.1074/jbc.272.37.23427

[15] Izban, M.G. and Luse, D.S. (1992) Factor-Stimulated RNA Polymerase II Transcribes at Physiological Elongation Rates on Naked DNA but Very Poorly on Chromatin Templates. The Journal of Biological Chemistry, 267, 1364713655.

[16] Hota, S.K. and Bartholomew, B. (2011) Diversity of Operation in ATP-Dependent Chromatin Remodelers. Biochimica et Biophysica Acta (BBA)—Gene Regulatory Mechanisms, 1809, 476-487. http://dx.doi.org/10.1016/j.bbagrm.2011.05.007

[17] Eitoku, M., Sato, L., Senda, T. and Horikoshi, M. (2008) Histone Chaperones: 30 Years from Isolation to Elucidation of the Mechanisms of Nucleosome Assembly and Disassembly. Cellular and Molecular Life Sciences, 65, 414-444. http://dx.doi.org/10.1007/s00018-007-7305-6

[18] Tagami, H., Ray-Gallet, D., Almouzni, G. and Nakatani, Y. (2004) Histone H3.1 and H3.3 Complexes Mediate Nucleosome Assembly Pathways Dependent or Independent of DNA Synthesis. Cell, 116, 51-61. http://dx.doi.org/10.1016/S0092-8674(03)01064-X

[19] Szenker, E., Ray-Gallet, D. and Almouzni, G. (2011) The Double Face of the Histone Variant H3.3. Cell Research, 21, 421-434. http://dx.doi.org/10.1038/cr.2011.14

[20] Avvakumov, N., Nourani, A. and Cote, J. (2011) Histone Chaperones: Modulators of Chromatin Marks. Molecular Cell, 41, 502-514. http://dx.doi.org/10.1016/j.molcel.2011.02.013

[21] Burgess, R.J. and Zhang, Z. (2010) Histones, Histone Chaperones and Nucleosome Assembly. Protein \& Cell, 1, 607612. http://dx.doi.org/10.1007/s13238-010-0086-y

[22] Tang, Y., Poustovoitov, M.V., Zhao, K., Garfinkel, M., Canutescu, A., Dunbrack, R., et al. (2006) Structure of a Human ASF1a-HIRA Complex and Insights into Specificity of Histone Chaperone Complex Assembly. Nature Structural \& Molecular Biology, 13, 921-929. http://dx.doi.org/10.1038/nsmb1147

[23] Tang, Y., Puri, A., Ricketts, M.D., Rai, T.S., Hoffmann, J., Hoi, E., et al. (2012) Identification of an Ubinuclein 1 Region Required for Stability and Function of the Human HIRA/UBN1/CABIN1/ASF1a Histone H3.3 Chaperone Complex. Biochemistry, 51, 2366-2377. http://dx.doi.org/10.1021/bi300050b

[24] Rai, T.S., Puri, A., McBryan, T., Hoffman, J., Tang, Y., Pchelintsev, N.A., et al. (2011) Human CABIN1 Is a Functional Member of the Human HIRA/UBN1/ASF1a Histone H3.3 Chaperone Complex. Molecular and Cellular Biology, 31, 4107-4118. http://dx.doi.org/10.1128/MCB.05546-11

[25] Lamour, V., Lecluse, Y., Desmaze, C., Spector, M., Bodescot, M., Aurias, A., et al. (1995) A Human Homolog of the S. cerevisiae $H I R_{1}$ and $H I R_{2}$ Transcriptional Repressors Cloned from the DiGeorge Syndrome Critical Region. Human Molecular Genetics, 4, 791-799. http://dx.doi.org/10.1093/hmg/4.5.791

[26] Lorain, S., Demczuk, S., Lamour, V., Toth, S., Aurias, A., Roe, B.A., et al. (1996) Structural Organization of the WD Repeat Protein-Encoding Gene HIRA in the DiGeorge Syndrome Critical Region of Human Chromosome 22. Genome Research, 6, 43-50. http://dx.doi.org/10.1101/gr.6.1.43

[27] Magnaghi, P., Roberts, C., Lorain, S., Lipinski, M. and Scambler, P.J. (1998) HIRA, a Mammalian Homologue of Saccharomyces cerevisiae Transcriptional Co-Repressors, Interacts with Pax3. Nature Genetics, 20, 74-77. 
http://dx.doi.org/10.1038/1739

[28] Banumathy, G., Somaiah, N., Zhang, R., Tang, Y., Hoffmann, J., Andrake, M., et al. (2009) Human UBN1 Is an Ortholog of Yeast Hpc2p and Has an Essential Role in the HIRA/ASF1a Chromatin-Remodeling Pathway in Senescent Cells. Molecular and Cellular Biology, 29, 758-770. http://dx.doi.org/10.1128/MCB.01047-08

[29] Daganzo, S.M., Erzberger, J.P., Lam, W.M., Skordalakes, E., Zhang, R., Franco, A.A., et al. (2003) Structure and Function of the Conserved core of Histone Deposition Protein Asf1. Current Biology, 13, 2148-2158. http://dx.doi.org/10.1016/j.cub.2003.11.027

[30] Prochasson, P., Florens, L., Swanson, S.K., Washburn, M.P. and Workman, J.L. (2005) The HIR Corepressor Complex Binds to Nucleosomes Generating a Distinct Protein/DNA Complex Resistant to Remodeling by SWI/SNF. Genes \& Development, 19, 2534-2539. http://dx.doi.org/10.1101/gad.1341105

[31] Osley, M.A. and Lycan, D. (1987) Trans-Acting Regulatory Mutations That Alter Transcription of Saccharomyces cerevisiae Histone Genes. Molecular and Cellular Biology, 7, 4204-4210.

[32] Dimova, D., Nackerdien, Z., Furgeson, S., Eguchi, S. and Osley, M.A. (1999) A Role for Transcriptional Repressors in Targeting the Yeast Swi/Snf Complex. Molecular Cell, 4, 75-83. http://dx.doi.org/10.1016/S1097-2765(00)80189-6

[33] Wunsch, A.M. and Lough, J. (1987) Modulation of Histone H3 Variant Synthesis during the Myoblast-Myotube Transition of Chicken Myogenesis. Developmental Biology, 119, 94-99. http://dx.doi.org/10.1016/0012-1606(87)90210-7

[34] Ray-Gallet, D., Quivy, J.P., Scamps, C., Martini, E.M., Lipinski, M. and Almouzni, G. (2002) HIRA Is Critical for a Nucleosome Assembly Pathway Independent of DNA Synthesis. Molecular Cell, 9, 1091-1100. http://dx.doi.org/10.1016/S1097-2765(02)00526-9

[35] Anderson, H.E., Wardle, J., Korkut, S.V., Murton, H.E., Lopez-Maury, L., Bahler, J., et al. (2009) The Fission Yeast HIRA Histone Chaperone Is Required for Promoter Silencing and the Suppression of Cryptic Antisense Transcripts. Molecular and Cellular Biology, 29, 5158-5167. http://dx.doi.org/10.1128/MCB.00698-09

[36] Llevadot, R., Scambler, P., Estivill, X. and Pritchard, M. (1996) Genomic Organization of TUPLE1/HIRA: A Gene Implicated in DiGeorge Syndrome. Mammalian Genome: Official Journal of the International Mammalian Genome Society, 7, 911-914. http://dx.doi.org/10.1007/s003359900268

[37] Loppin, B., Bonnefoy, E., Anselme, C., Laurencon, A., Karr, T.L. and Couble, P. (2005) The Histone H3.3 Chaperone HIRA Is Essential for Chromatin Assembly in the Male Pronucleus. Nature, 437, 1386-1390. http://dx.doi.org/10.1038/nature04059

[38] Roberts, C., Sutherland, H.F., Farmer, H., Kimber, W., Halford, S., Carey, A., et al. (2002) Targeted Mutagenesis of the Hira Gene Results in Gastrulation Defects and Patterning Abnormalities of Mesoendodermal Derivatives Prior to Early Embryonic Lethality. Molecular and Cellular Biology, 22, 2318-2328. http://dx.doi.org/10.1128/MCB.22.7.2318-2328.2002

[39] Balaji, S., Iyer, L.M. and Aravind, L. (2009) HPC2 and Ubinuclein Define a Novel Family of Histone Chaperones Conserved Throughout Eukaryotes. Molecular BioSystems, 5, 269-275. http://dx.doi.org/10.1039/b816424j

[40] Aho, S., Lupo, J., Coly, P.A., Sabine, A., Castellazzi, M., Morand, P., et al. (2009) Characterization of the Ubinuclein Protein as a New Member of the Nuclear and Adhesion Complex Components (NACos). Biology of the Cell, 101, 319334. http://dx.doi.org/10.1042/BC20080072

[41] Gruffat, H., Lupo, J., Morand, P., Boyer, V. and Manet, E. (2011) The Nuclear and Adherent Junction Complex Component Protein Ubinuclein Negatively Regulates the Productive Cycle of Epstein-Barr Virus in Epithelial Cells. Journal of Virology, 85, 784-794. http://dx.doi.org/10.1128/JVI.01397-10

[42] Elsaesser, S.J. and Allis, C.D. (2010) HIRA and Daxx Constitute Two Independent Histone H3.3-Containing Predeposition Complexes. Cold Spring Harbor Symposia on Quantitative Biology, 75, 27-34. http://dx.doi.org/10.1101/sqb.2010.75.008

[43] Schwabish, M.A. and Struhl, K. (2006) Asf1 Mediates Histone Eviction and Deposition during Elongation by RNA Polymerase II. Molecular Cell, 22, 415-422. http://dx.doi.org/10.1016/j.molcel.2006.03.014

[44] Shandilya, J. and Roberts, S.G. (2012) The Transcription Cycle in Eukaryotes: From Productive Initiation to RNA Polymerase II Recycling. Biochimica et Biophysica Acta (BBA)—Gene Regulatory Mechanisms, 1819, 391-400. http://dx.doi.org/10.1016/j.bbagrm.2012.01.010

[45] Orphanides, G., Lagrange, T. and Reinberg, D. (1996) The General Transcription Factors of RNA Polymerase II. Genes \& Development, 10, 2657-2683. http://dx.doi.org/10.1101/gad.10.21.2657

[46] Wada, T., Takagi, T., Yamaguchi, Y., Ferdous, A., Imai, T., Hirose, S., et al. (1998) DSIF, a Novel Transcription Elongation Factor That Regulates RNA Polymerase II Processivity, Is Composed of Human $\mathrm{Spt}_{4}$ and $\mathrm{Spt}_{5} \mathrm{Homologs}_{\text {. Genes }}$ \& Development, 12, 343-356. http://dx.doi.org/10.1101/gad.12.3.343

[47] Yamaguchi, Y., Takagi, T., Wada, T., Yano, K., Furuya, A., Sugimoto, S., et al. (1999) NELF, a Multisubunit Com- 
plex Containing RD, Cooperates with DSIF to Repress RNA Polymerase II Elongation. Cell, 97, 41-51. http://dx.doi.org/10.1016/S0092-8674(00)80713-8

[48] Corden, J.L. (1990) Tails of RNA Polymerase II. Trends in Biochemical Sciences, 15, 383-387. http://dx.doi.org/10.1016/0968-0004(90)90236-5

[49] Ohkuma, Y. and Roeder, R.G. (1994) Regulation of TFIIH ATPase and Kinase Activities by TFIIE during Active Initiation Complex Formation. Nature, 368, 160-163. http://dx.doi.org/10.1038/368160a0

[50] Liu, X., Bushnell, D.A., Silva, D.A., Huang, X. and Kornberg, R.D. (2011) Initiation Complex Structure and Promoter Proofreading. Science, 333, 633-637. http://dx.doi.org/10.1126/science.1206629

[51] Peterlin, B.M. and Price, D.H. (2006) Controlling the Elongation Phase of Transcription with P-TEFb. Molecular Cell, 23, 297-305. http://dx.doi.org/10.1016/j.molcel.2006.06.014

[52] Ivanov, D., Kwak, Y.T., Guo, J. and Gaynor, R.B. (2000) Domains in the SPT5 Protein That Modulate Its Transcriptional Regulatory Properties. Molecular and Cellular Biology, 20, 2970-2983. http://dx.doi.org/10.1128/MCB.20.9.2970-2983.2000

[53] Lis, J. (1998) Promoter-Associated Pausing in Promoter Architecture and Postinitiation Transcriptional Regulation. Cold Spring Harbor Symposia on Quantitative Biology, 63, 347-356. http://dx.doi.org/10.1101/sqb.1998.63.347

[54] Gilchrist, D.A., Fromm, G., dos Santos, G., Pham, L.N., McDaniel, I.E., Burkholder, A., et al. (2012) Regulating the Regulators: The Pervasive Effects of Pol II Pausing on Stimulus-Responsive Gene Networks. Genes \& Development, 26, 933-944. http://dx.doi.org/10.1101/gad.187781.112

[55] Muse, G.W., Gilchrist, D.A., Nechaev, S., Shah, R., Parker, J.S., Grissom, S.F., et al. (2007) RNA Polymerase Is Poised for Activation across the Genome. Nature Genetics, 39, 1507-1511. http://dx.doi.org/10.1038/ng.2007.21

[56] Donahue, B.A., Yin, S., Taylor, J.S., Reines, D. and Hanawalt, P.C. (1994) Transcript Cleavage by RNA Polymerase II Arrested by a Cyclobutane Pyrimidine Dimer in the DNA Template. Proceedings of the National Academy of Sciences of the United States of America, 91, 8502-8506. http://dx.doi.org/10.1073/pnas.91.18.8502

[57] Tornaletti, S. and Hanawalt, P.C. (1999) Effect of DNA Lesions on Transcription Elongation. Biochimie, 81, $139-146$. http://dx.doi.org/10.1016/S0300-9084(99)80046-7

[58] Toulme, F., Guerin, M., Robichon, N., Leng, M. and Rahmouni, A.R. (1999) In Vivo Evidence for Back and Forth Oscillations of the Transcription Elongation Complex. The EMBO Journal, 18, 5052-5060. http://dx.doi.org/10.1093/emboj/18.18.5052

[59] Zenkin, N., Yuzenkova, Y. and Severinov, K. (2006) Transcript-Assisted Transcriptional Proofreading. Science, 313, 518-520. http://dx.doi.org/10.1126/science.1127422

[60] Nudler, E. (2012) RNA Polymerase Backtracking in Gene Regulation and Genome Instability. Cell, 149, $1438-1445$. http://dx.doi.org/10.1016/j.cell.2012.06.003

[61] Jeon, C. and Agarwal, K. (1996) Fidelity of RNA Polymerase II Transcription Controlled by Elongation Factor TFIIS. Proceedings of the National Academy of Sciences of the United States of America, 93, 13677-13682. http://dx.doi.org/10.1073/pnas.93.24.13677

[62] Larson, M.H., Zhou, J., Kaplan, C.D., Palangat, M., Kornberg, R.D., Landick, R., et al. (2012) Trigger Loop Dynamics Mediate the Balance between the Transcriptional Fidelity and Speed of RNA Polymerase II. Proceedings of the National Academy of Sciences of the United States of America, 109, 6555-6560. http://dx.doi.org/10.1073/pnas.1200939109

[63] Ratner, J.N., Balasubramanian, B., Corden, J., Warren, S.L. and Bregman, D.B. (1998) Ultraviolet Radiation-Induced Ubiquitination and Proteasomal Degradation of the Large Subunit of RNA Polymerase II. Implications for Transcription-Coupled DNA Repair. The Journal of Biological Chemistry, 273, 5184-5189. http://dx.doi.org/10.1074/jbc.273.9.5184

[64] Somesh, B.P., Reid, J., Liu, W.F., Sogaard, T.M., Erdjument-Bromage, H., Tempst, P., et al. (2005) Multiple Mechanisms Confining RNA Polymerase II Ubiquitylation to Polymerases Undergoing Transcriptional Arrest. Cell, 121, 913923. http://dx.doi.org/10.1016/j.cell.2005.04.010

[65] Hershko, A. and Ciechanover, A. (1998) The Ubiquitin System. Annual Review of Biochemistry, 67, 425-479. http://dx.doi.org/10.1146/annurev.biochem.67.1.425

[66] Anindya, R., Aygun, O. and Svejstrup, J.Q. (2007) Damage-Induced Ubiquitylation of Human RNA Polymerase II by the Ubiquitin Ligase Nedd4, but Not Cockayne Syndrome Proteins or BRCA1. Molecular Cell, 28, 386-397. http://dx.doi.org/10.1016/j.molcel.2007.10.008

[67] Yasukawa, T., Kamura, T., Kitajima, S., Conaway, R.C., Conaway, J.W. and Aso, T. (2008) Mammalian Elongin A Complex Mediates DNA-Damage-Induced Ubiquitylation and Degradation of Rpb1. The EMBO Journal, 27, 32563266. http://dx.doi.org/10.1038/emboj.2008.249 
[68] Harreman, M., Taschner, M., Sigurdsson, S., Anindya, R., Reid, J., Somesh, B., et al. (2009) Distinct Ubiquitin Ligases Act Sequentially for RNA Polymerase II Polyubiquitylation. Proceedings of the National Academy of Sciences of the United States of America, 106, 20705-20710. http://dx.doi.org/10.1073/pnas.0907052106

[69] Wilson, M.D., Harreman, M. and Svejstrup, J.Q. (2013) Ubiquitylation and Degradation of Elongating RNA Polymerase II: The Last Resort. Biochimica et Biophysica Acta (BBA)—Gene Regulatory Mechanisms, 1829, 151-157. http://dx.doi.org/10.1016/j.bbagrm.2012.08.002

[70] Kwak, J., Workman, J.L. and Lee, D. (2011) The Proteasome and Its Regulatory Roles in Gene Expression. Biochimica et Biophysica Acta (BBA)—Gene Regulatory Mechanisms, 1809, 88-96. http://dx.doi.org/10.1016/j.bbagrm.2010.08.001

[71] Bedford, L., Paine, S., Sheppard, P.W., Mayer, R.J. and Roelofs, J. (2010) Assembly, Structure, and Function of the 26S Proteasome. Trends in Cell Biology, 20, 391-401.

[72] Glickman, M.H., Rubin, D.M., Coux, O., Wefes, I., Pfeifer, G., Cjeka, Z., et al. (1998) A Subcomplex of the Proteasome Regulatory Particle Required for Ubiquitin-Conjugate Degradation and Related to the COP9-Signalosome and eIF3. Cell, 94, 615-623. http://dx.doi.org/10.1016/S0092-8674(00)81603-7

[73] Anderson, H.E., Kagansky, A., Wardle, J., Rappsilber, J., Allshire, R.C. and Whitehall, S.K. (2010) Silencing Mediated by the Schizosaccharomyces Pombe HIRA Complex Is Dependent upon the Hpc2-Like Protein, Hip4. PIOS ONE, 5, e13488. http://dx.doi.org/10.1371/journal.pone.0013488

[74] Ray-Gallet, D., Woolfe, A., Vassias, I., Pellentz, C., Lacoste, N., Puri, A., et al. (2011) Dynamics of Histone H3 Deposition in Vivo Reveal a Nucleosome Gap-Filling Mechanism for H3.3 to Maintain Chromatin Integrity. Molecular Cell, 44, 928-941. http://dx.doi.org/10.1016/j.molcel.2011.12.006

[75] Chujo, M., Tarumoto, Y., Miyatake, K., Nishida, E. and Ishikawa, F. (2012) HIRA, a Conserved Histone Chaperone, Plays an Essential Role in Low-Dose Stress Response via Transcriptional Stimulation in Fission Yeast. The Journal of Biological Chemistry, 287, 23440-23450. http://dx.doi.org/10.1074/jbc.M112.349944

[76] DeSilva, H., Lee, K. and Osley, M.A. (1998) Functional Dissection of Yeast Hir1p, a WD Repeat-Containing Transcriptional Corepressor. Genetics, 148, 657-667.

[77] Andrulis, E.D., Guzman, E., Doring, P., Werner, J. and Lis, J.T. (2000) High-Resolution Localization of Drosophila Spt5 and Spt6 at Heat Shock Genes in Vivo: Roles in Promoter Proximal Pausing and Transcription Elongation. Genes \& Development, 14, 2635-2649. http://dx.doi.org/10.1101/gad.844200

[78] Formosa, T., Ruone, S., Adams, M.D., Olsen, A.E., Eriksson, P., Yu, Y., et al. (2002) Defects in SPT16 or POB3 (yFACT) in Saccharomyces cerevisiae Cause Dependence on the Hir/Hpc Pathway: Polymerase Passage May Degrade Chromatin Structure. Genetics, 162, 1557-1571.

[79] Chimura, T., Kuzuhara, T. and Horikoshi, M. (2002) Identification and Characterization of CIA/ASF1 as an Interactor of Bromodomains Associated with TFIID. Proceedings of the National Academy of Sciences of the United States of America, 99, 9334-9339. http://dx.doi.org/10.1073/pnas.142627899

[80] Bhat, K.P. and Greer, S.F. (2011) Proteolytic and Non-Proteolytic Roles of Ubiquitin and the Ubiquitin Proteasome System in Transcriptional Regulation. Biochimica et Biophysica Acta (BBA)—Gene Regulatory Mechanisms, 1809, 150-155. http://dx.doi.org/10.1016/j.bbagrm.2010.11.006

[81] Ishizuka, T., Satoh, T., Monden, T., Shibusawa, N., Hashida, T., Yamada, M., et al. (2001) Human Immunodeficiency Virus Type 1 Tat Binding Protein-1 Is a Transcriptional Coactivator Specific for TR. Molecular Endocrinology, 15, 1329-1343. http://dx.doi.org/10.1210/mend.15.8.0680

[82] Satoh, T., Ishizuka, T., Tomaru, T., Yoshino, S., Nakajima, Y., Hashimoto, K., et al. (2009) Tat-Binding Protein-1 (TBP-1), an ATPase of 19S Regulatory Particles of the 26S Proteasome, Enhances Androgen Receptor Function in Cooperation with TBP-1-Interacting Protein/Hop2. Endocrinology, 150, 3283-3290. http://dx.doi.org/10.1210/en.2008-1122

[83] Dianov, G.L., Houle, J.F., Iyer, N., Bohr, V.A. and Friedberg, E.C. (1997) Reduced RNA Polymerase II Transcription in Extracts of Cockayne Syndrome and Xeroderma Pigmentosum/Cockayne Syndrome Cells. Nucleic Acids Research, 25, 3636-3642. http://dx.doi.org/10.1093/nar/25.18.3636

[84] Salinas-Rios, V., Belotserkovskii, B.P. and Hanawalt, P.C. (2011) DNA Slip-Outs Cause RNA Polymerase II Arrest in Vitro: Potential Implications for Genetic Instability. Nucleic Acids Research, 39, 7444-7454. http://dx.doi.org/10.1093/nar/gkr429

[85] Lyu, Y.L., Kerrigan, J.E., Lin, C.P., Azarova, A.M., Tsai, Y.C., Ban, Y., et al. (2007) Topoisomerase II $\beta$ Mediated DNA Double-Strand Breaks: Implications in Doxorubicin Cardiotoxicity and Prevention by Dexrazoxane. Cancer Research, 67, 8839-8846. http://dx.doi.org/10.1158/0008-5472.CAN-07-1649

[86] Zhang, S., Liu, X., Bawa-Khalfe, T., Lu, L.S., Lyu, Y.L., Liu, L.F., et al. (2012) Identification of the Molecular Basis of Doxorubicin-Induced Cardiotoxicity. Nature Medicine, 18, 1639-1642. http://dx.doi.org/10.1038/nm.2919 